\title{
Evaluation of the procedures of people applying to the psychiatry outpatient clinics to remove their past diagnosis
}

\author{
Sare Aydin ${ }^{1}$, Sedat Batmaz $^{2}$, Esma Akpinar Aslan $^{1}{ }^{(}$, Zekiye Celikbas $^{3}$ \\ 'Tokat Gaziosmanpasa University Faculty of Medicine, Department of Psychiatry, Tokat, Turkey \\ ${ }^{2}$ Social Sciences University, Faculty of Humanities and Social Sciences, Department of Psychology (Applied Psychology), Ankara, \\ Turkey \\ ${ }^{3}$ Fethiye State Hospital, Department of Psychiatry, Mugla, Turkey
}

Dear Editor,

Recently, it has been observed that people have applied to psychiatry outpatient clinics to have their diagnosis and treatment records removed, claiming that their previous diagnosis of mental disorders is wrong.

Psychiatric disorders are diagnosed using the history obtained from the person and their relatives, mental state examination during the interview, past medical documents, and psychometric assessment tools. If the signs and symptoms that meet the diagnostic criteria are so severe that they lead to a decrease in the functionality of the person in occupational, social, interpersonal, and other areas for a certain period of time, the presence of a mental disorder can be mentioned. For example, if a psychotropic drug is to be prescribed when a mental disorder is detected, it is recommended to be used for the period specified in the current treatment guidelines. Whether the person has benefited from the treatment is evaluated according to the clinical opinion or standard assessment tools as a result of the history and mental state examination taken during the interview (1).

On the other hand, the absence of signs and symptoms indicating a previous diagnosis of a mental disorder in the last mental status examination does not invalidate the diagnosis made in the past. Because many mental disorders are chronic and show a periodic course. For this reason, the person may not have any signs or symptoms at the time of evaluation, or may have disappeared as a result of the treatments applied to the individual, and/or their existence may be denied by the individuals during the evaluation, they are expressed differently from what they actually are, and their severity may be underestimated, etc. Considering all these reasons, it may not always be possible to form a definite clinical opinion about the diagnosis made in the past. However, explaining this situation in detail to all applicants in this way causes unnecessary workload and loss of time (1).

Since it is seen in the medical board reports requested during the application to the relevant institutions that people who will serve with weapons such as specialized sergeants, non-commissioned officers, police officers, and neighborhood wardens had psychiatric applications in the past, it prevents them from starting work. For this reason, people who encounter this obstacle apply to have their previous mental disorder diagnoses removed, resting on the letter of the Ministry of Health General Directorate of Health Information Management Systems dated 21.05.2019 and numbered 555 and the Ministry's

How to cite this article: Aydin S, Batmaz S, Akpinar Aslan E, Celikbas Z. Evaluation of the procedures of people applying to the psychiatry outpatient clinics to remove their past diagnosis. Dusunen Adam The Journal of Psychiatry and Neurological Sciences 2021;34:392-393.

Correspondence: Sare Aydin, Tokat Gaziosmanpasa University Faculty of Medicine, Department of Psychiatry, Tokat, Turkey 
consent letter "Misreported Diagnoses" dated 17.05.2019 and numbered 546. (2).

The mental health of those who will use a gun during duty is important both for the risk of self-harm of the person who will use the gun and for public safety due to their duties. For this reason, both the Security Organization Health Conditions Regulation (3) prepared and issued by the Ministry of Internal Affairs, General Directorate of Security and the Health Competence Regulation (4) of the Turkish Armed Forces Gendarmerie General Command and the Coast Guard Command attach great importance to the evaluation of mental health. Considering the second paragraph of the 23rd article of the section for the recruitment examination of the specialized sergeants, contracted sergeants and privates, and candidates under the Turkish Armed Forces, Gendarmerie General Command and Coast Guard Command Health Competence Regulation, there is a statement as they 'must be fully sound in terms of mental health and diseases'. This statement requires that the candidate has not received any psychiatric referrals and has not received any psychiatric treatment in the past. In this case, the candidate's job application will not be accepted. Again, in the ANNEX-3 of the Security Health Conditions Regulation of the General Directorate of Security, Security Organization Health Conditions Regulation (Amendment: OG-29/9/2019-30903), the phrase "they will be mentally sound" is included. Afterward, the criterion of being mentally healthy was explained as "Spent the last two years without symptoms and treatment is considered psychiatrically healthy". However, while it is aimed to protect the person who will serve in the armed forces and other members of the society with the relevant articles and criteria, it causes restrictions on the personal rights of the person. At the same time, the fact that people who need psychiatric support do not apply to the psychiatry clinic due to their concerns about the process they will experience in their job application causes the treatment not to be arranged, the progression of undiagnosed and untreated mental disorders, and this situation creates more serious problems after the person starts armed duty. It also reinforces the stigma of psychiatric patients (5).

While on the one hand restrictions were imposed on the applications of those who received psychiatric support in the past, on the other hand, in some institutions, medical board examinations of applicants are carried out in the daily polyclinic routine in a short examination period, which leads to the neglection of some traits, which should be evaluated with detailed history and some tests, such as impulse and anger control, ability to adapt to the profession and cause risky people to go undetected. Moreover, in these occupational groups with a high risk of experiencing mental trauma, candidates' mental health and risky behaviors should be evaluated at regular intervals after they start their profession.

Considering all these, to improve the relevant legislation, special committees should be established for determining certain risk situations for all candidates, regardless of whether they have had psychiatric applications in the past, and they should be evaluated in these committees before their job applications. Through these committees, it would be possible to recognize some mental disorders that may be less related to risky situations such as impulse and anger control disorder as past and improved for candidates, to check the candidates when necessary, as well as the periodic psychological evaluations of candidates after taking office. In this way, it can be argued that the legislation can be made more functional in terms of both the assessment of the professional adaptation of the person after starting the armed service and the protection of the personal rights of individuals who have applied for psychiatric disorders in the past.

Peer-review: Externally peer-reviewed.

Conflict of interest: The authors declared no potential conflicts of interest with respect to the research, authorship, and/or publication of this article.

Financial Disclosure: The authors received no financial support for the research, authorship, and/or publication of this article.

\section{REFERENCES}

1. Sadock BJ, Sadock VA, Ruiz P. Examination and Diagnosis of the Psychiatric Patient Bozkurt A, editor. Kaplan \& Sadock Psychiatry Behavioral Sciences/Clinical Psychiatry. Eleventh ed., Ankara: Güneş Kitap Evleri; 2016.

2. Letter of the Ministry of Health General Directorate of Health Information Management Systems dated 21.05.2019 and numbered 555 and the Ministry's consent letter "Misreported Diagnoses" dated 17.05.2019 and numbered 546

3. Security Organization Health Conditions Regulation published in the Official Gazette dated 3/1/2018 and numbered 30290

4. Health Competence Regulation of the of the Turkish Armed Forces Gendarmerie General Command and the Coast Guard Command published in the Official Gazette dated 11/11/2016 and numbered 29885.

5. Baysal GOD. Stigmatization and mental health. Arşiv Kaynak Tarama Dergisi 2013; 22:239-251. 